\title{
Ensuring Sustainability of Polio Immunization in Health System Transition: Lessons from the Polio Eradication Initiative in Indonesia
}

\section{Luthfi Azizatunnisa'}

Universitas Gadjah Mada Fakultas Kedokteran: Universitas Gadjah Mada Fakultas Kedokteran

Kesehatan Masyarakat dan Keperawatan

\section{Utsamani Cintyamena}

Gadjah Mada University Faculty of Medicine: Universitas Gadjah Mada Fakultas Kedokteran Kesehatan Masyarakat dan Keperawatan

\section{Yodi Mahendradhata}

Gadjah Mada University Faculty of Medicine: Universitas Gadjah Mada Fakultas Kedokteran Kesehatan Masyarakat dan Keperawatan

Riris Andono Ahmad ( $\nabla$ risandono.ahmad@gmail.com )

Universitas Gadjah Mada https://orcid.org/0000-0001-9340-3922

\section{Research article}

Keywords: sustainability, maintenance, immunization, polio, implementation research, implementation science, health system, decentralization, health system transition

Posted Date: December 1st, 2020

DOI: https://doi.org/10.21203/rs.3.rs-115160/v1

License: (c) (1) This work is licensed under a Creative Commons Attribution 4.0 International License. Read Full License 


\section{Abstract}

Background: Sustaining an effective evidence-based health intervention will maximize its impact in public health. Political and governmental reforms impact immunization program sustainability both positively and negatively. This study aims to explore sustainability of polio immunization in a decentralized health system taking lessons learned from a polio eradication initiative in Indonesia.

Methods: We collected qualitative data through in-depth interviews with 27 key informants in from various backgrounds at district, provincial, and national levels, consisting of frontline workers, managers and NGOs at national and sub-national level. We conducted thematic analysis and triangulated using document reviews. We also conducted member checking and peer debriefing to ensure trustworthiness.

Results: Competing priority was identified as the major challenge to sustain government commitment for polio immunization and AFP surveillance during the transition toward a decentralized health system. Variation of local government capacities has also affected immunization delivery and commitment at sub-national level government. The government reform has led to a more democratic society, which is also conducive for rejection and vaccine hesitancy. Multi sector partnership has been identified to play a big role in maintaining polio immunization coverage. Strong and continuous advocacy and campaign are essential to raise awareness for the community and policy makers to maintain the high polio immunization coverage.

Conclusion: Competing priority was the major factor that affected high coverage of polio immunization during the decentralization transition. Strong advocacy is needed at every level, from district to national level, to keep polio immunization prioritized.

\section{Background}

Sustainability has been defined as "the extent to which an intervention is maintained or institutionalized in a given setting" $(1,2)$. Planning for program sustainability is a key contributor to health and development, especially in low-and middle-income countries (LMICs). Maintaining sustainability has been identified as a necessary effort to maximize public health impacts of evidence-based intervention (3). Most concerns about sustainability are related to premature discontinuation of a program after the initial period of support (4). Aside from the unmet needs, the discontinuation of beneficial programs are wasteful of human, financial, and technical investment. Moreover, failure to maintain sustainability of programs in community settings may result in low levels of community support, trust in public health institutions, and support for future programs (3-5). Throughout all of the elements described in many papers, four general domains of sustainability have been identified: ensuring supportive context (political, organizational, and environmental), capacity building (stakeholders and community), effective partnerships and relationships, and rigorous decision making and planning (6).

Immunization has been long identified as an effective intervention to control vaccine preventable diseases (VPDs) such as polio. Indonesia introduced polio immunization into the routine immunization 
program in 1981. Following the World Health Assembly (WHA) 1988, Indonesia initiated a polio eradication initiative in 1991. The Government of the Republic of Indonesia had strong commitment to implement this policy which resulted in polio elimination in 1995. However, challenges to maintain the sustainability of the immunization program were faced during political and governmental reform in 1998 . GAVI has defined immunization sustainability as "the ability of a country to mobilize and effectively use domestic and supplementary external resources on a reliable basis to achieve current and future target levels of immunization performance in terms of access, utilization, quality, safety, and equity". With political and economic transitions, the sustainability of immunization could also shift (7). Political and governmental reforms impact the health system and therefore affect health programs, including immunization (8).

Health system reform refers to a process of changing the system of health to improve efficiency. Health system reform had been identified to have an impact on immunization. Reforms likely involve operational changes in immunization management (8). The decentralized health system gave the opportunity to extend the standards developed for immunization to other aspect of primary health care, thus it could reinforce good management practices and build up capacity. The health reform also provides opportunity to consider new approaches to funding arrangements for supporting immunization, especially in procuring specialized equipment (8). Beside the benefits, many obstacles were identified in immunization during the health reform period and transition; these included human resource, organizational, socioeconomic, and legal challenges. Major changes in the health system and government system reform thus affected the sustainability of the polio eradication initiative that had been built for years. A previous study suggested that routine immunization suffered a significant fall due to decentralization (9). Another study demonstrated that decentralization is related to lower levels of childhood immunization coverage (10).

Many studies have reported the impact of decentralization on the health system and healthcare services. However, during the literature review, we none has focused on investigating the impact of decentralization on the sustainability of the polio eradication initiative. This study aimed to explore the sustainability of polio immunization during health system transition, by taking lessons learned from polio eradication initiatives in Indonesia.

\section{Methods}

\section{Study design}

This study is a qualitative case study. In-depth interviews and document review were conducted as data collection methods. In-depth interviews were conducted face-to-face and by phone. Phone interviews were conducted to several participants when face-to-face interviews were not feasible due to scheduling and geographical challenges. Reviews of polio related documents and reports were conducted to support qualitative findings and for triangulation.

\section{Context}


Before 1999, Indonesia's government system was centralized. In 1999, Law Number 22 on Regional Development was implemented giving full authority to districts/municipalities to rule and be responsible for the governance of their own area. During this time, the political and social landscapes were also shifting from authoritarianism to democracy and decentralization. Following this political reform, Indonesia's health system was also transitioned to decentralized system (11).

The Indonesian health system is supported by public and private providers, as well as public and private financing. The public system is administered through a decentralized government system, with central, provincial and district government involvement. However, in the decentralized health system, the relationship between The Ministry of Health $(\mathrm{MoH})$, Provincial Health Office (PHO) and District Health Office (DHO) is not hierarchical. The district government is not under the provincial government. Each level has its own mandates and areas of authority $(11,12)$.

Since 2001, the number of provinces has expanded from 26 to 34. Since decentralization, there have been significant regional disparities in terms of health status and in the quality, availability, and capacity of health services. This transition has affected the capacity of the $\mathrm{MoH}$ to implement health programs and maintain integration and alignment across the different levels of the health system. However, the MoH still has a few vertical programs that directly function at provincial and district level, such as immunization (11).

The polio eradication program is under the responsibility of the Directorate General of Disease Control and Prevention (DGDC) and implemented by the Directorate of Surveillance and Health Quarantine (DSHQ) within DGDC. Within DSHQ, polio immunization implementation sits within the Sub-directorate of Immunization while Acute Flaccid Paralysis (AFP) surveillance is under the Sub-directorate of Surveillance. Meanwhile, the responsibility for vaccine procurement is held by the Directorate of Pharmacy and Health Equipment (DPHE); responsibility for the health laboratories falls under the Directorate General of Medical Services; and the responsibility for developing information, education and communication (IEC) material is under Directorate of Health Promotion (13).

At the provincial and district level, $\mathrm{PHO}$ and DHO supervise hospitals and health centers as the implementers of the program. Local governments are responsible for the delivery of immunization programs in their areas, but the central government remains responsible for additional immunization activities; providing vaccines, syringes and needles; technical assistance; developing guidelines; monitoring and evaluation; maintaining quality; and training $(11,13)$.

\section{Study participants}

Purposive snowball sampling techniques were applied to recruit study participants with rich information on polio eradication in Indonesia. Study participants were from national and subnational levels, and frontline workers with various affiliations and backgrounds. Study participants had worked on polio eradication for at least 12 months during the period of 1988-2018. The final number of participants was achieved after reaching data saturation. 


\section{Study setting}

The study was conducted by recruiting participants at national and subnational level. Six provinces were selected purposively to represent major challenges faced in polio eradication in Indonesia. They are Yogyakarta, West Java, Banten, East Java, Aceh and East Nusa Tenggara. Yogyakarta was selected because it was the pilot province for IPV and also the first province that switched to IPV. West Java and East Java were selected due to the WPV and VDPV outbreaks which occurred in 2005. Banten was selected because the WPV outbreak spread to Banten and according to MoH reports, immunizationrejection was highly prevalent in Banten. Aceh was selected because the last WPV case was found in Aceh province in 2006. East Nusa Tenggara was selected as representative of the eastern part of Indonesia, with major geographical and infrastructural challenges. In-depth interviews were conducted during January-March 2019. Document reviews were conducted from December 2018 to May 2019.

\section{Data collection procedures}

Potential participants (polio key informants) were listed. Interviews were scheduled by making appointments with them. The study was explained to participants and they were given time to discuss and clarify. If participants agreed to be interviewed, they were asked to sign informed consent. For phone interviews, verbal consent was sought. Interviews were conducted using an interview guide which had been piloted to the immunization and surveillance program managers at PHO of Yogyakarta prior to data collection. Interviews were performed in Bahasa Indonesia by two research assistants who have been trained on Good Health Research Practices (14). Interviews were recorded using a digital audio recorder. Recordings were transcribed into verbatim transcripts. Thematic analysis was applied to analyze the data. Confidentiality of the data was ensured by making the transcript and data in the final report anonymous. The ethical clearance was obtained from the Medical and Health Research Ethic Committee (MHREC), Faculty of Medicine, Public Health and Nursing, Universitas Gadjah Mada, Indonesia (Approval Number: KE/FK/0757/EC/2018).

\section{Analysis}

Thematic analysis was applied and transcripts were coded into meaningful units. Similar codes were grouped into categories and themes were generated from these categories. Linkages between themes were then identified. A sustainability framework by Schell (2013) was applied for analysis (15). The analysis was performed using OpenCode 4.03 software (https://www.umu.se/en/department-ofepidemiology-and-global-health/research/open-code2/). Peer debriefing, member checking and triangulation were conducted to ensure validity.

\section{Result}

\section{Participants}


We listed 10 potential participants for in-depth interviews. During the data collection process, the participants recommended other potential participants and snowball sampling was applied. In total, we interviewed 27 key informants consisting of 16 from the national level, 7 from the sub-national level, and 4 frontline workers from various institutional backgrounds (Table 1). Face-to-face interviews were conducted with 22 participants and phone interviews were conducted with 5 participants.

Table 1

Characteristic of Key Informant Interview (KII) Participants

\begin{tabular}{|lll|}
\hline Variables & Group & N \\
\hline Age & $30-39$ & 1 \\
\hline & $40-49$ & 6 \\
\hline Gender & $50-59$ & 10 \\
\hline & $\geq 60$ & 10 \\
\hline Polio related affiliation & Central level government & 11 \\
\hline & Provincial government & 4 \\
\hline & District government & 2 \\
\hline & Frontline worker & 4 \\
\hline Interview method & NGo & 1 \\
\hline & Partners (WHO, UNICEF) & 5 \\
\hline & Face-to-face & 22 \\
\hline
\end{tabular}

\section{Polio History}

Indonesia has a long history of polio immunization (Fig. 1). Indonesia first introduced an immunization program in 1973 with BCG immunization. Immunization expanded to include TT and DPT in 1974 and 1976. In the following year, 1977, Extended Program in Immunization (EPI) was initiated using WHO global immunization guidelines in 55 health centers. During the same years, EPI Basic Guidelines were developed for Indonesia. In 1981 OPV was added to the EPI with 4 doses of tOPV. In 1995 the last indigenous poliovirus was reported. In 2005, imported WPV was detected in Sukabumi, West Java, and later caused outbreak with a total of 305 cases reported in several provinces. Apart from WPV outbreak, there was VDPVs outbreak in Madura, East Java. The last poliovirus was detected in Aceh Tenggara in 2006. Indonesia, along with SEAR countries, was granted polio-free certification in 2014. In 2016, the government implemented tOPV, switching to bOPV and introducing IPV. 


\section{Sustainability Components}

This study found that sustainability components affected each other and led to declining immunization coverage during health system transition, summarized in Fig. 2. Using predetermined sustainability framework, this study developed nine themes and 18 categories (Table 2)

Table 2

Themes and Categories

\begin{tabular}{|c|c|c|}
\hline No & Themes & Categories \\
\hline \multirow[t]{3}{*}{1} & \multirow[t]{3}{*}{ Political support } & Competing priority at national and sub-national level \\
\hline & & Disparities at subnational level \\
\hline & & Preventive measure was not priority in health budget allocation \\
\hline \multirow[t]{2}{*}{2} & \multirow[t]{2}{*}{ Funding stability } & Decreased health budget during the transition \\
\hline & & Low health budget allocation at sub-national level \\
\hline 3 & Partnership & $\begin{array}{l}\text { Collapsed Puskesmas (Primary Health Center - PHC) and Posyandu } \\
\text { (Integrated health post) }\end{array}$ \\
\hline \multirow[t]{2}{*}{4} & \multirow{2}{*}{$\begin{array}{l}\text { Organizational } \\
\text { capacity }\end{array}$} & Insufficient leadership capacity among policy makers at sub-national level \\
\hline & & $\begin{array}{l}\text { Differences in human resource capacity at national level before and after } \\
\text { decentralization }\end{array}$ \\
\hline 5 & $\begin{array}{l}\text { Program } \\
\text { adaptation }\end{array}$ & Adaptation of funding sources \\
\hline 6 & $\begin{array}{l}\text { Program } \\
\text { evaluation }\end{array}$ & Supervision of district was decreased \\
\hline \multirow[t]{2}{*}{7} & \multirow[t]{2}{*}{ Communication } & There was gap of advocacy capacity among the sub-national levels \\
\hline & & Decreased socialization \\
\hline \multirow[t]{4}{*}{8} & \multirow[t]{4}{*}{ Public impact } & Vaccine hesitancy \\
\hline & & Legal issue due to AEFI \\
\hline & & Involving key persons as a strategy tackling anti-vaccine movement \\
\hline & & NID was perceived as the biggest community movement in health \\
\hline \multirow[t]{2}{*}{9} & \multirow{2}{*}{$\begin{array}{l}\text { Strategic } \\
\text { planning }\end{array}$} & No significant impact of decentralization on polio strategic planning \\
\hline & & $\begin{array}{l}\text { The characteristics of polio eradication initiative as contributing factor for } \\
\text { the success of the program }\end{array}$ \\
\hline
\end{tabular}

Political Support 
Competing priority has been identified as the major challenge to sustain polio-related activities during a health system transition. Priority in districts may have changed, therefore not all districts may have allocated adequate amounts of money for polio eradication, resulting in decreased quality or quantity of polio-related activities. Moreover, during government transition, most of the national budget was allocated for political and governmental purposes, therefore, the health budget was cut (Fig. 2). This impacted polio immunization coverage in the following years. It was reported that the coverage dropped and then outbreak occurred in 2005 (Fig. 3). The non-Polio AFP rate was also impacted with a slight decrease during the transition (Fig. 4). It increased dramatically in 2005 due to the WHO supported Surveillance Officers (SOs) at every province, enacted in 2002.

During transition from a centralized to decentralized system, maternal and child immunization coverage and availability remained pressing issues at the district level in Indonesia. Complete child immunization in most districts in Indonesia was below the WHO recommendation threshold of $80 \%$ (12). In 2002, complete child immunization coverage in central java (Cilacap, Rembang, Jepara, Pemalang, Brebes) and East Java (Trenggalek, Jombang, Ngawi, Sampang, Pamekasan) was below 51\%, with the lowest level at 9\% in Sampang district, East Java (12).

"... with democracy process in district, they choose their own leader (mayor), of course the priority of each district is different... The most important thing is to convince the policy makers both at central and district level that this (polio) is priority, this is an investment and will give huge impact" (Informant 9, Manager at National level).

\section{Disparities at sub-national level}

The reforms also caused disparities between local governments. Disparities become a threat to health due to the new leaderships' lack of understanding and awareness around funding for health services; this is especially true in poor districts or municipalities. To ensure that local government undertake certain public measures, the $\mathrm{MoH}$ issued a decree in 2005 pertaining to 26 types of minimum/essential public health services that the local government must perform. Of these 26 services, 16 are related to public health such as maternal and child health, promotion and prevention of prevalent diseases, school health and disease surveillance (16). However, five years after the enactment of this policy, it was reported that not all district governments applied all of the indicators mentioned in this policy.

\section{Preventive measure was not priority in health budget allocation}

Many local governments were more interested in curative health care such as constructing new facilities or refurbishing existing hospitals, rather than strengthening the public health infrastructure. In addition, local governments are more concerned over the shortages of medical officers, rather than closing the gaps for deployment of public health professionals (16). 
"... we conduct advocacy to the government to develop minimum service standard (SPM) where the districts have to have indicators for polio. Though, it is applied for immunization, I think it is not powerful enough" (Informant 17, Technical Assistant at National Level)

\section{Funding Stability}

\section{Decreased health budget during the transition}

At the central level during the transition, national budget was concentrated on government reform. Health budget was reduced and the priority was curative. Therefore, the budget for promotion and prevention was decreased (Fig. 2). This severely impacted immunization supervision and surveillance. The supervision for immunization received less priority and less funding. Therefore, the coverage of polio immunization decreased during the transition (Fig. 3). Moreover, the polio-free status obtained since 1995 made the government complacent about the AFP surveillance, thus the NPAFP rate decreased during transition (Fig. 4).

"...during the transition, government focus was on funding the government reform. Health budget was cut. Moreover, the priority was for curative..." (Informant 25, Manager at National level)

Even though a decentralized health system has been applied, vaccine procurement has remained centralized. Funds for procuring and supplying regular vaccines for immunization programs were mainly sourced from the APBN (National Budget and Expenditure) and managed by the Director General of Pharmaceuticals and Medical Devices, $\mathrm{MoH}$. For the delivery, $\mathrm{MoH}$ shared the costs with the district governments.

"...the difference is that now, programs become more integrated and cost sharing is applied" (Informant 5, Technical Assistant at National level)

\section{Low health budget at sub-national level}

Decentralization allowed the local government to develop and finance local initiative health programs. However, the implementation of health programs in each local government depends on local fiscal capacity, regulation, and political process. Meanwhile, one of the impacts of decentralization led to widening the fiscal capacity gap between local governments. However, in both poor and rich local governments, the health budget from the general allocation fund (Dana Alokasi Umum/DAU) and APBD was not enough to fund the healthcare services. In several districts, budget constraints were more common after decentralization due to public health budget reduction (12).

The inadequate budget for healthcare at local government resulted in disruptions within the health system and lost coordination. Central government initiated the increase de-concentration budget through Specific Allocation Fund (DAK - Dana Alokasi Khusus) for the health sector. Therefore, central government still funded the highest amount of the health budget during the transition (Fig. 5). 
The central government established minimum service standards for public services to standardize which public services must exist, including immunization. Immunization is also included in Children Protection Laws, Health Laws, and Regional Government Laws stating that immunization is a must for all children in Indonesia. These regulations required every district government to allocate budget for immunization. However, roughly half of all districts do not allocate the mandated $10 \%$ of local budgets to health. This affects the allocation for immunization service delivery, increasing immunization outreach, and maintenance of cold chain equipment (7).

\section{Partnerships}

\section{Collapsed Puskesmas (Primary Health Center - PHC) and Posyandu (Integrated health post)}

Community mobilization is pivotal in immunization programs. Front line workers at PHC and integrated health posts at village level, where immunization was delivered, played an important role for community mobilization. However, lack of sufficient health funding at district level has encouraged more Puskesmas to become self-funded, for example by instituting additional charges for service delivery. As immunization was mostly delivered at PHC, the lower income families could not afford the additional health service fees and withdrew from this facility, further jeopardizing their health status. Moreover, during the decentralization transition, many people financially suffered as a result of from the monetary crisis (18, 19). Figure 6 demonstrates that the contact rates to the public hospital, PHC and Posyandu decreased during the transition.

Furthermore, in 1997, Posyandu attendance by children under 5 was $57 \%$, already below complete coverage. It fell further in 1998 to just 42\%. Susenas (National Socio-Economic Household Survey) 1995, 1997 and 1998 show similar trends, while province-specific surveys during the crisis revealed low contact rates for public facilities and a large share of Posyandu as inactive (19). This affected immunization coverage. In the following years, the coverage dropped and outbreak occurred in 2005 (Fig. 3). This shows how important community engagement was for immunization.

"...In 98 we experienced multi-dimensional crisis, monetary crisis. Therefore, Mr. President had to step down. Back then our strength for immunization was Posyandu (integrated health post), after the crisis, Posyandu collapsed" (Informant 4, Former Manager at National Level)

\section{Organizational Capacity}

\section{Insufficient leadership capacity among policy makers at sub-national level}

The development of local health programs was influenced by the local capacity and political process. During the transition, it was reported that the capability and capacity of local government was not 
adequate in planning, budgeting, and utilizing their budget effectively and efficiently. Local government's actions in allocating insufficient funding to health budgets may be due to poor judgment on the part of decision makers. Therefore, this disparity hindered local progress in developing capacity (20). Inadequate leadership and vision among bureaucrats at local level were identified as major factors that influenced local government to continue implementing the old system even after decentralization, rather than answering the current health related needs and problems, such as immunization and polio.

"Decentralization is necessary, but it was supposed to be well prepared. Capacity building for the policy makers at district level need to be conducted prior to the enactment. From my point of view, districts capacities were not ready for decentralization. They were still dependent to the central level" (Informant 6 , Manager at National level)

\section{Differences in human resource capacity at national level before and after decentralization}

Several informants reported that there were differences in terms of human resource capacity at national level before and after reformation. Prominent leadership and governance issues were identified during the decentralization transition; this included issues around transparency, accountability, health strategy, guideline implementation, and system design (12), which affected the health-related decisions and policies they made.

"... The quality of human resources decreased and that nepotism emerged. People who were smart, and should be promoted, were pushed away. Those who could not stand anymore, resigned and moved to WHO, UNICEF. I was really sad. Those who got promoted are those who did not have any achievement" (Informant 6, Manager at National level)

\section{Program Adaptation}

\section{Adaptation of funding sources}

During the transition, the most significant change made was the funding source, as previously it had been central government which funded the program. After decentralization the program fund was the responsibility of the national and sub-national government together. However, there was still division of responsibility. National Government was responsible for procurement and providing guidelines; provincial government was responsible for supervision and technical assistance; and, district government was responsible for operations and delivery. Each responsibility was funded by each level budget. However, this funding stream may not be smooth and adequately allocated. Budget allocation has been explained in the funding stability section.

\section{Program Evaluation}

\section{Supervision of district was decreased}


In the decentralized health system, supervision from the central level shifted to provincial level, therefore supervision of the districts should be conducted by each province. However, as all provinces do not have adequate resources, supervision of the districts or municipalities became a challenge. Therefore, supervision of the districts, especially for surveillance, decreased within the decentralized health system (Fig. 2).

"What's the impact of decentralization? Economic became number one, efficiency. Budget was cut. Health budget was cut. Therefore, the quantity of supervision to the health post decreased" (Informant 25, Technical Assistant at National level)

"With the decentralization enacted, central level cannot directly supervise district, the supervision is only up to province level. Province is the one which has responsibility to supervise district. This is also a challenge, because provinces do not have sufficient resources to do so. Therefore, the supervision on AFP surveillance performance decreased" (Informant 3, Technical Assistant at National level)

Coordination and review meetings were held regularly at provincial and national level to maintain communication of polio networks and to evaluate the performance of AFP surveillance performance. This activity was supported by external funding (WHO) by hiring a surveillance officer (SO) at the provincial level, which started in 2002.

\section{Communications}

\section{There was gap of advocacy capacity among the sub- national levels}

As there was competing priority at district level after decentralization, strong and continuous advocacy for polio immunization became essential. Advocacy should be conducted at national level (within the $\mathrm{MOH}$ as well as other Ministries such as Home Affairs and Planning), and at the provincial and district/municipalities level. Unfortunately, the capacity for advocacy within the sub-national governments varied. There was a huge gap between those who already had the capacity and those who did not, therefore capacity building for advocacy was required. An advocacy consultant was also hired to plan effective advocacy strategies.

"What we can do is to convince the policy makers... thus advocacy has to be our mandatory activity. However, the capacity to conduct advocacy seems to be insufficient. We need a motivator, communication specialist, advocate to convince local government, local representative board in order to allocate resources for polio" (Informant 3, Technical Assistant at National level)

\section{Public Health Impacts}

\section{Vaccine hesitancy}


The first NIDs conducted in 1995 were very festive and engaging as most people voluntarily participated in this event, although some hesitancies existed in a small percent of people. After decentralization, where freedom of speech was assured and information was more freely spread, there was more rejection to immunization. For example, during a mop-up campaign in 2005, there were negative media reports which incorrectly blamed the polio vaccine for a number of coincidental adverse events during the first round of immunization, causing misunderstanding and suspicion among public.

\section{Legal issue due to AEFI}

After decentralization, democracy was more widely implemented and the awareness of freedom of speech increased. This gave rise to legal issues known as an Adverse Event Following Immunization (AEFI). After decentralization, the number of health staff who were sued due to AEFI increased. This made health staff afraid to deliver immunization services, and they requested protection to carry out their duties. The strategy taken by the $\mathrm{MoH}$ was to develop national immunization guidelines as Ministry Decree. Previously, the guidelines were signed by the authority at directorate general level, which was not strong enough to become legal basis for health staff carrying out their responsibilities. This change enabled health staff to have legal assurance when they work in adherence to the guidelines.

"...in centralized era we did not really care about legal standing of regulation so we only made national guidelines signed only by director general. When AEFI occurred, there was no fuss and suing or legal action. After reformation, due to arisen legal issue, health staff became afraid to give vaccination. They pushed us to develop national guidelines as MoH decree" (Informant 6, Manager at National level)

\section{Involving key persons as a strategy tackling anti-vaccine movement}

Many strategies and measures were implemented to tackle the negativity against vaccinations, such as using the role of professional organizations to take action against doctors who opposed vaccines, and using multi-modal interventions to raise the awareness of the community.

"I even attended the seminar on anti-vaccine to counter their arguments. I challenge that person to argue with scientific evidence. I don't know how I could be very brave back then, hahaha" (Informant 5, Manager at National level)

Sensitization of community and stakeholders was intensively conducted during the polio campaign. Ulama, public figures, community leaders and other champions were involved in socialization to convince the community that immunization is very important. Various media sources were used for community sensitization such as roadshows, printed media, mass media, electronic media, and social media to counter the negative campaign against immunization that intensified after decentralization. However, most of the informants stated that the quantity and integration of sensitization efforts have decreased.

"...in socialization we engaged MUI (Indonesian Ulama Council) to give endorsement (fatwa)... we also made polio campaign in TV starred by famous celebrity... We engage many brands to support the 


\section{NID was perceived as the biggest community movement in health}

Though routine immunization has been provided since 1977, the peak of the immunization campaign came with the first NIDs in 1995. It was so exciting and has been claimed as the largest community mobilization for health. The eventful NIDs provided a strong impression upon the community and the polio eradication campaign increased community awareness on overall immunization, extending further than just polio. Therefore, the community perceived that immunization is a health need, not simply an enforced obligation.

"Massive polio campaign has increased the awareness of community on immunization. Immunization has become their needs" (Informant 1, frontline worker)

\section{Strategic Planning}

\section{No significant impact of decentralization on polio strategic planning}

There is no significant impact of decentralization on polio strategic planning. Most of the informants mentioned that there was no difference in the polio program before and after decentralization because the Indonesian government follows a global polio policy. The implementation of polio immunization follows the updated recommendation from WHO. In 2012, the World Health Assembly declared polio as a public health emergency and expressed the need for a comprehensive endgame strategy. WHO developed a polio eradication and endgame strategic plan for 2013-2018. Indonesia started to implement the polio endgame strategy to maintain polio-free status and to achieve the global target of polio eradication in 2020. Following the updated strategic plan, Indonesia conducted switching from tOPV to bOPV and introduced one dose IPV to enhance and strengthen the immunization program. Poliovirus containment and environmental survey were also added into the activities.

"We have prepared for transition process. The process has been run well enough. The document has also been developed. Our roadmap has also been adjusted to the global roadmap on polio eradication. We have implemented switching, improving surveillance, and improving laboratories' capacity to ensure the eradication process succeed" (Informant 9, Manager at National level)

\section{The characteristics of polio eradication initiative as contributing factor for the success of the program}


Regardless of many challenges faced during the implementation, most informants mention that the success of the polio eradication initiative was because of the characteristics of the program. Clear and detailed plans, targets, strategies and impacts were identified as the factors that facilitated the implementation of the polio eradication initiative. This clear detail also attracted multi sectors and partners to become involved in polio-related activities.

"Polio eradication has clear detailed program, clear goal and target. With the same goal, the role of each actors were also clear, so that it attracted partners to involve..." (Informant 21, Polio Partners at National level)

\section{Discussion}

The sustainability of the immunization program may have been compromised due to political, economic and structural transitions during the reform era. Competing priority has been identified as a major factor that lead to several challenges in immunization sustainability such as decreased budget, decreased supervision, decreased priority on preventive efforts, and inadequate leadership capacity. In addition, vaccine hesitancy was also reported more after reformation due to the implementation of democracy. As polio has been included in routine immunization since 1981, it was also impacted by the transition.

Competing interest for public funds as well as economic slow-downs during reformation affected immunization financing and sustainability. Previous studies suggest that there is a clear association between decentralization and a weakened immunization program $(7,21)$. Increased autonomy at the subnational level opens doors for an increased number of actors to affect the prioritization of immunization programs, while also introducing new challenges for ensuring high performance on national immunization. The political will and political leadership of sub-national units may be the only and most important factor related to the immunization performance (7). Without proper accountability, a decentralized health system can be problematic for immunization and other health programs. Along with The Philippines, Indonesia is reported to be the most heavily decentralized countries in the Asia Pacific and both are having trouble delivering program goals, resulting in decreasing immunization coverage rates (7).

Immunization is still vertically funded by the central government, which has signaled the prioritization of immunization in the country. However, the reliance on macroeconomic growth and political prioritization is not enough to sustain the immunization program (7). To improve prioritization across a decentralized health system, there are a range of potential approaches to take into account: engaging with sub-national governments as advocacy partners regarding immunization financing; supporting research to analyze ways in which current center-local relationships exist; and, direct engagement for improved outcomes through promoting ongoing policy and practice dialogue at both national and sub-national level (7). However, the results of the study suggest that the advocacy capacity of local government was lacking during the transition and continued to do so until recently. 
The partial division on vaccine procurement and service delivery responsibility between national and subnational level has led to uncertain program ownership (possibly exacerbated by differing priorities at local level) and has almost certainly played a part in the stagnation of immunization coverage since decentralization (22). Previous studies have identified that the weaknesses of immunization during the decentralization transition were due to budgeting for vaccine purchase, national procurement practices, performance of national regulatory agencies, and technical capacity for vaccine planning and advocacy $(7,23)$.

Establishing immunization policy and legislation for a standard of service delivery is also essential to build a strong immunization program (24). Moreover, during the transition, more private healthcare facilities were established, thus private providers developed higher prominence than those from the public sector. Therefore, the regulation on the guideline for immunization delivery is very important as a standard and to ensure the quality of delivery among various providers (7). Several previous studies reported that SPM (minimal service standard) in the health sector could improve health status, and therefore could improve family welfare. However, implementation for immunization and family planning is still lacking, and requires improvement to increase performance $(25,26)$.

In terms of the sustainability of financing for health programs, the country is pushing to diversify their resources. Diversified sources of funding help to mitigate the risk of political maneuvering or economic downturns, as well as open avenues to increase the overall health budget. As most of the expenditure of immunization programs are on the procurement of vaccines, operational needs can often have less priority. The responsibility of setting priorities is shifting to domestic stakeholders, which may assist this. However, the capacity of sub-national government in achieving targeted coverage also varies. Not all practices and approaches implemented in high coverage area are replicable in other areas. Therefore, there are basic planning, budgeting, and delivery functions that can be improved in low performing settings through application of improved accountability mechanisms, ongoing coaching, and copying of approaches from higher performing settings (7).

As decentralization aims to manage resources more efficiently based on each districts' needs, the integration of health programs becomes more prevalent for the purpose of efficiency. Integration of immunization programs with other public health services, such as breastfeeding, maternal nutrition, community midwifery etc. are more effective. A commonly integrated program allows health workers of various units to take up immunization related activities as their responsibility (24).

Many studies have identified community ownership and mobilization as essential for intervention sustainability, at both the beginning of and during the intervention implementation. Involving stakeholders and providing them with a sense of ownership in intervention proved beneficial for a variety of reasons (27). A previous study suggests that community-provider partnership has been proven to increase immunization coverage (28). Another study also suggests that increasing the number of Posyandu (integrated health post) per 1000 population significantly improves the probability of children 
receiving full immunization, while increasing the number of hospitals and Puskesmas (Public Health Center) has no significant effect (22).

Volunteerism is also important in intervention sustainability. Community volunteers perceived their role in the program as similar to other community health workers and thus showed good ownership of the intervention and were ready to take on various responsibilities to continue the intervention $(24,27)$. Nongovernmental sectors also play a significant role in immunization services, regardless of whether the government sector proactively engages them (28).

High quality data are pivotal to empower immunization program management, to increase vaccine uptake and to reach unvaccinated children. Meanwhile, ensuring the quality and effectiveness of surveillance and public health response is a critical challenge in developing countries in an environment of decentralization. There exists several health systems barriers that constrained the effectiveness of the intervention in influencing the availability of data, analysis and response (29). Utilization of traditional methods, such as home-based vaccination recording, and newer technology, such as information communication and technology tools, are reported to be able to improve data quality on timeliness and accuracy, while also contributing to improved immunization coverage $(24,30)$.

Delegating responsibility to various community workers is key for the sustainability of an intervention. Better monitoring and program evaluation is needed to sustain interventions (27). Besides regular coordination meetings at national, provincial, district and health facility level, involving the private sector, organizations, community leaders, and volunteers can provide timely feedback to improve the immunization delivery services (24).

The lack of community awareness or education regarding the health issues also impeded successful implementation and intervention sustainability. Vaccine hesitancy has been reported in more than $90 \%$ countries in the world, while media platforms (including social media) has been identified as enormously influential in the spread of vaccine hesitancy. Pediatricians and family doctors have a key role in convincing parents of the benefits of vaccination. However, pediatricians and family doctors acting alone are not sufficient to overcome vaccine hesitancy; governments and health policy makers also play an essential role in promoting vaccination, educating the general community, and implementing policies that reduce the public health risks associated with vaccine hesitancy $(31,32)$.

Community mobilization has been central to NIDs by mobilizing various community organizations; however, this social mobilization had not been utilized to improve the chronic problems with routine immunization and surveillance (33). To address these problems, having champions was very important to ensure sustainability. The organizational representatives that reported high champion effectiveness were most likely to be from organizations that sustained health interventions (34).

Information, Education and Communication (IEC) strategies have been widely used and showed positive results. Various media on polio campaigns have been identified to have a significant impact, such as radio, television, religious organizations, and interpersonal communication between caretaker and 
community leaders and health workers (33). Lesson learned from the communication strategy is the need for integrated media especially when communities are filled with negative rumors or reject vaccination. (33). Utilizing the integrated and combination of all types of communication channels provides a better chance to change mindsets than using a single channel approach (31). Communication programs for polio eradication have made a number of contributions for capacity building such as developing micro plans, organizing social mobilization, conducting advocacy among policy makers, dealing successfully with negative campaigns and resistance, and identifying hard-to-reach populations (33).

The degree to which vaccinations provide broad public health benefits is stronger than for other preventive and curative interventions (35). Government leadership; evidence-based programing; countrydriven, comprehensive, and operational annual plans; community partnership; and, strong accountability systems are critical for programs. Polio eradication has illustrated that these can be leveraged to increase immunization coverage and equity and enhance global health security $(35,36)$.

A limitation of this study is reliance on qualitative data which might have the possibility of recall bias during data collection. The association made was also based on the experience of key informants. However, we minimized the bias by conducting document review for triangulation, peer debriefing, and member checking. Therefore, the findings from this study have been corroborated by several information resources.

\section{Conclusion}

Ensuring immunization sustainability is essential to maintain its effectiveness in the community, since immunization is the most cost-effective intervention for infectious disease control. In a decentralized health system, the sustainability of immunization is a challenge mainly due to the competing priority, inadequate local government capacity in managing the program implementation, and vaccine hesitancy. Strong advocacy and community sensitizatiob, and capacity building are instrumental to address those challenges.

\section{Abbreviations}

AEFI: Adverse Event Following Immunization; AFP: Acute Flaccid Paralysis; APBD: Anggaran Pendapatan dan Belanja Daerah/District or Province Revenue and Expenditure Budget; APBN: Anggaran Pendapatan dan Belanja Negara/National Revenue and Expenditure Budget; bOPV: bivalent Oral Polio Vaccine; DAK: Dana Alokasi Khusus/ Specific Allocation Fund; DAU: Dana Alokasi Umum/General Allocation Fund; DGDC: Directorate General of Disease Control; DHO: District Health Office; DPHE: Directorate of Pharmacy and Health Equipment; DPT: Diphtheria, Pertussis, Tetanus; DSHQ: Directorate Surveillance and Health Quarantine; EPI: Expanded Program in Immunization; GAVI: Global Alliance for Vaccines and Immunizations; IEC: Information, Education and Communication; IPV: Inactivated Polio Vaccine ; LMICs: Low and Middle Income Countries; MHREC: Medical and Health Research Ethical Committee; $\mathrm{MoH}$ : Ministry of Health; NIDs: National Immunization Days; PHC: Primary Health Care/Puskesmas; PHO: 
Provincial Health Office; SEAR: South East Asia Region; SO: Surveillance Officer; SPM: Standar Pelayanan Minimum/Minimum Service Standards; tOPV: trivalent Oral Polio Vaccine; TT: Tetanus Toxoid; VDPV: Vaccine Derived Poliovirus; VPDs: Vaccine Preventable Diseases

\section{Declarations}

\section{Ethics approval and consent to participate}

Ethical approval was obtained from Medical and Health Research Ethics Committee (MHREC) Faculty of Medicine, Public Health and Nursing, Universitas Gadjah Mada, Indonesia with approval number KE/FK/0757/EC/2018. Informed consent were obtained from all participants prior to their participation in the study.

\section{Consent for publication}

Not applicable.

\section{Availability of data and materials}

Data and materials supporting the findings are available from corresponding author on reasonable request.

\section{Competing interest}

The authors declare that they do not have competing interests.

\section{Funding}

This study is funded by The Bill and Melinda Gates Foundation as part of consortium study entitled Synthesis and Translation of Research and Innovation from Polio Eradication (STRIPE) conducted in 7 countries led by John Hopkins University. The funder had no role in the design of the study and collection, analysis, and interpretation of data and in writing the manuscript.

\section{Authors' Contributions}

Data collection was conducted by LA and UC. LA, UC, YM, RAA contributed in data analysis and manuscript drafting. All authors involved in reviewing, revising the manuscript, and approving the final manuscript. 


\section{Acknowledgement}

We would like to convey our gratitude to John Hopkins University; Dr. Jane Soepardi; Dr. Nyoman Kandun; Dr. Julitasari Sundoro; Dr. Hariadi Wibisono; Dr. Samhari Baswedan; Directorate General of Surveillance and Health Quarantine, Ministry of Health of Republic of Indonesia; Provincial Health Office (PHO) of Yogyakarta, West Java, East Java, Banten, Aceh, and East Nusa Tenggara; WHO Indonesia; UNICEF Indonesia; Rotary Indonesia, BioFarma.

\section{Authors' information}

${ }^{1}$ Department of Health Behavior, Environment and Social Medicine, Faculty of Medicine, Public Health and Nursing, Universitas Gadjah Mada, Yogyakarta, Indonesia

${ }^{2}$ Center for Tropical Medicine, Faculty of Medicine, Public Health and Nursing, Universitas Gadjah Mada, Yogyakarta, Indonesia

${ }^{3}$ Department of Health Policy and Management, Faculty of Medicine, Public Health and Nursing, Universitas Gadjah Mada, Yogyakarta, Indonesia

${ }^{4}$ Department of Biostatistics, Epidemiology and Population Health, Faculty of Medicine, Public Health and Nursing, Universitas Gadjah Mada, Yogyakarta, Indonesia

\section{References}

1. Peters DH, Adam T, Alonge 0 , Agyepong IA, Tran N. Implementation research: What it is and how to do it. BMJ [Internet]. 2013;347(November):1-7. Available from: http://dx.doi.org/doi:10.1136/bmj.f6753

2. Peters DH, Tran NT, Adam T. Implementation Research in Health: a practical guide. Alliance for Health Policy and Systems Research, World Health Organization. 2013.

3. Shelton R, Cooper BR, Stirman SW. The Sustainability of Evidence-Based Interventions and Practices in Public Health and Health Care. Ssrn. 2018;

4. Gruen RL, Elliott JH, Nolan ML, Lawton PD, Parkhill A, McLaren CJ, et al. Sustainability science: an integrated approach for health-programme planning. Lancet [Internet]. 2008;372(9649):1579-89. Available from: http://dx.doi.org/10.1016/S0140-6736(08)61659-1

5. Mijumbi R. How can the sustainability of a public health program be ensured? SURE Rapid Response. 2011.

6. Whelan J, Love P, Pettman T, Doyle J, Booth S, Smith E, et al. Cochrane Update: Predicting sustainability of intervention effects in public health evidence: Identifying key elements to provide guidance. J Public Heal (United Kingdom). 2014;36(2):347-51.

7. Coe M, Gergen J, Philu C, Ozaltin A. Sustainable Immunization Financing in Asia Pacific. 2017. 
8. Feilden R, Nielsen OF, World Health Organization. Dept. of Vaccines and Biologicals. Immunization and health reform: making reforms work for immunization: a reference guide / prepared for WHO/V\&B/EPI. 2001;21. Available from: http://www.who.int/iris/handle/10665/69617

9. Yoong J. Does Decentralization Hurt Childhood Immunization? Dep Econ Standford Univ [Internet]. 2007;(October):1-39. Available from: http://citeseerx.ist.psu.edu/viewdoc/download? doi=10.1.1.370.4021\&rep=rep1\&type=pdf

10. Khaleghian P. Decentralization and public services: The case of immunization. Soc Sci Med. 2004;59(1):163-83.

11. Mahendradhata $Y$, Trisnantoro L, Listyadewi S, Soewondo P, Marthias T, Harmurti P, et al. The Republic of Indonesia Health System Review [Internet]. Vol. 7, World Health Organization. 2017. 1291 p. Available from: http://apps.who.int/iris/bitstream/10665/254716/1/9789290225164-eng.pdf

12. Rakmawati T, Hinchcliff R, Pardosi JF. District-level impacts of health system decentralization in Indonesia: A systematic review. Int J Health Plann Manage. 2019;(February):1-28.

13. Thorley M, Soenardi W. Sustainability Planning for Maintaining Indonesia 's Polio-Free Status. 2017.

14. Mahendradhata Y, Nabieva J, Ahmad RA, Henley P, Launois P, Merle C, et al. Promoting good health research practice in low- and middle-income countries. Glob Health Action. 2016;9(1):32474.

15. Schell SF, Luke DA, Schooley MW, Elliott MB, Herbers SH, Mueller NB, et al. Public health program capacity for sustainability: A new framework. Implement Sci [Internet]. 2013;8(1):1. Available from: Implementation Science

16. Thabrany $\mathrm{H}$. Human resources in decentralized health system in Indonesia: Challenges for equity. Reg Heal Forum. 2006;10(1):75-88.

17. Trisnantoro. L. Desentralisasi Kesehatan: Definisi dan Tinjauan Sejarah di Indonesia. 2008.

18. Kristiansen S, Santoso P. Surviving decentralisation?. Impacts of regional autonomy on health service provision in Indonesia. Health Policy (New York). 2006;77(3):247-59.

19. Lieberman SS, Marzoeki P. Health Strategy in a Post-Crisis, Decentralizing Indonesia. Washington DC; 2002.

20. Hidayat MS, Mahmood A, Moss J. Decentralisation in Indonesia: The Impact on Local Health Programs. J Kesehat Masy. 2018;12(2):68-77.

21. Kamara L, Milstien JB, Patyna M, Lydon P, Levin A, Brenzel L. Strategies for financial sustainability of immunization programs: A review of the strategies from 50 national immunization program financial

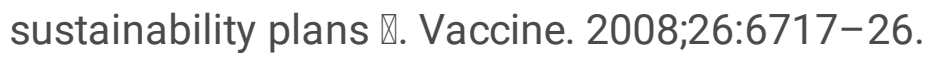

22. Maharani A, Tampubolon $G$. Has decentralisation affected child immunisation status in Indonesia? Glob Health Action. 2015;8(1):1-13.

23. Saxenian H, Hecht R, Kaddar M, Schmitt S, Ryckman T, Cornejo S. Overcoming challenges to sustainable immunization financing: Early experiences from GAVI graduating countries. Health Policy Plan. 2015;30(2):197-205. 
24. Paridah M., Moradbak A, Mohamed A., Owolabi F abdulwahab taiwo, Asniza M, Abdul Khalid SH. Implementation of Expanded Program on Immunization (EPI). Intech. 2016;i(tourism):13.

25. Rengga OA. Studi Impementasi Standar Pelayanan Minimal (Spm) Bidang Kesehatan Dasar Di Kota Magelang. Forum (Semarang). 2012;40(1):12-20.

26. Khozin M. Evaluasi Implementasi Kebijakan Standar Pelayanan Minimal Bidang Kesehatan Di Kabupaten Gunungkidu. J Stud Pemerintah. 2010;1(1):29-51.

27. Iwelunmor J, Blackstone S, Veira D, Nwaozuru U, Airhihenbuwa C, Munodawafa D, et al. Toward the sustainability of health interventions implemented in sub-Saharan Africa: A systematic review and conceptual framework. Implement Sci [Internet]. 2016;11(1). Available from:

http://dx.doi.org/10.1186/s13012-016-0392-8

28. Findley SE, Irigoyen M, See D, Sanchez M, Chen S, Sternfels P, et al. Community-Provider Partnerships to Reduce Immunization Disparities: Field Report from Northern Manhattan. Am J Public Health. 2003;93(7):1041-4.

29. Hotchkiss DR, Eisele TP, Djibuti M, Silvestre EA, Rukhadze N. Health system barriers to strengthening vaccine-preventable disease surveillance and response in the context of decentralization: Evidence from Georgia. BMC Public Health. 2006;6:1-10.

30. Saadatian-Elahi M, Bloom D, Plotkin S, Picot V, Louis J, Watson M. Vaccination ecosystem health check: Achieving impact today and sustainability for tomorrow. BMC Proc [Internet]. 2017;11(Suppl 2):1-6. Available from: http://dx.doi.org/10.1186/s12919-016-0069-y

31. Arede M, Bravo-Araya M, Bouchard É, Gill GS, Plajer V, Shehraj A, et al. Combating vaccine hesitancy: Teaching the next generation to navigate through the post truth era. Front Public Heal. 2019;6(JAN):1-6.

32. The Lancet Child \& Adolescent Health. Vaccine hesitancy: a generation at risk. Lancet Child Adolesc Heal [Internet]. 2019;3(5):281. Available from: http://dx.doi.org/10.1016/S2352-4642(19)30092-6

33. Waisbord S. Assessment of Communication Programs In Support of Polio Eradication: Global Trends and Case Studies [Internet]. 2004. Available from: http://pdf.usaid.gov/pdf_docs/PNADC156.pdf

34. Tomioka M, Braun KL. Examining Sustainability Factors for Organizations that Adopted Stanford's Chronic Disease Self-Management Program. Front Public Heal. 2015;2(April):1-8.

35. Wilder-Smith A, Longini I, Zuber PL, Bärnighausen T, Edmunds WJ, Dean N, et al. The public health value of vaccines beyond efficacy: Methods, measures and outcomes. BMC Med. 2017;15(1):1-9.

36. Van Den Ent MMVX, Mallya A, Sandhu H, Anya BP, Yusuf N, Ntakibirora M, et al. Experiences and Lessons from Polio Eradication Applied to Immunization in 10 Focus Countries of the Polio Endgame Strategic Plan. J Infect Dis. 2017;216(Suppl 1):S250-9.

\section{Figures}




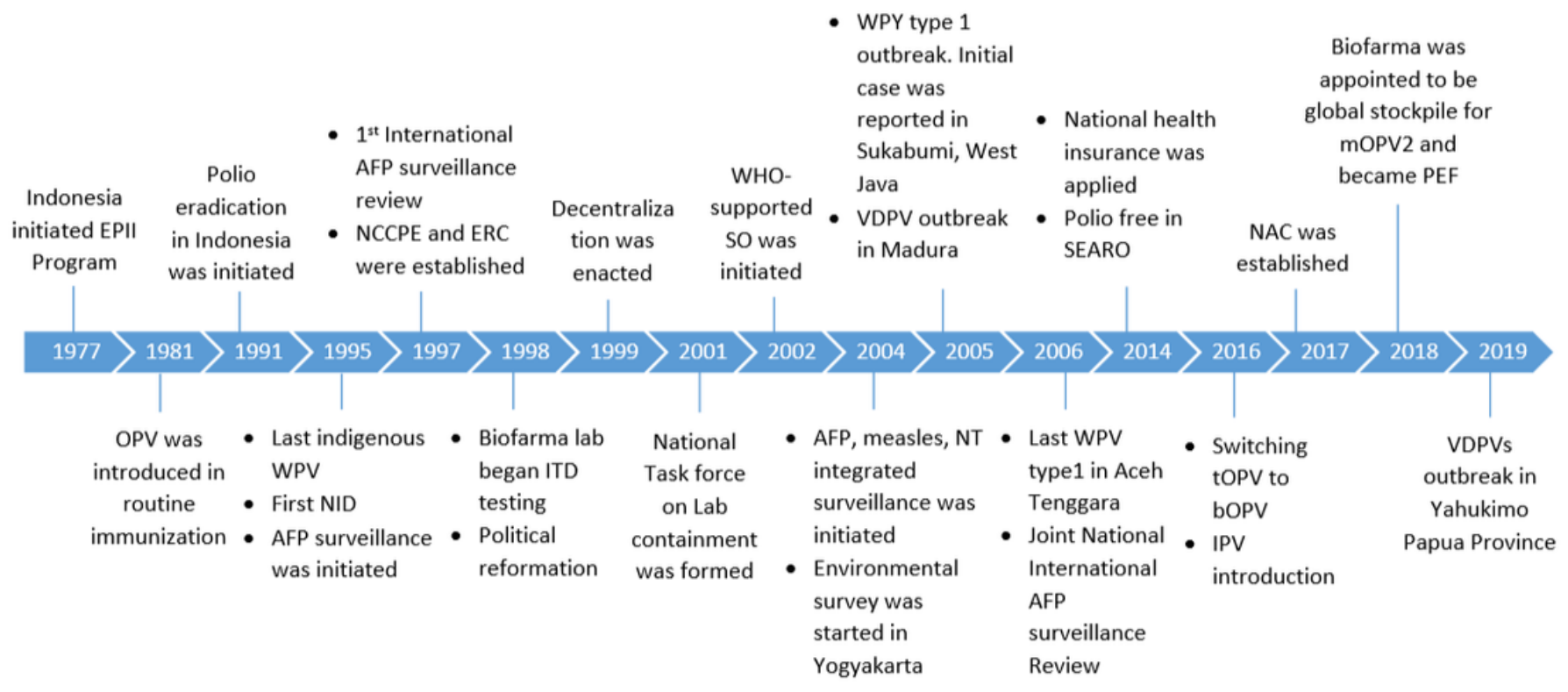

\section{Figure 1}

Timeline of Polio History in Indonesia 


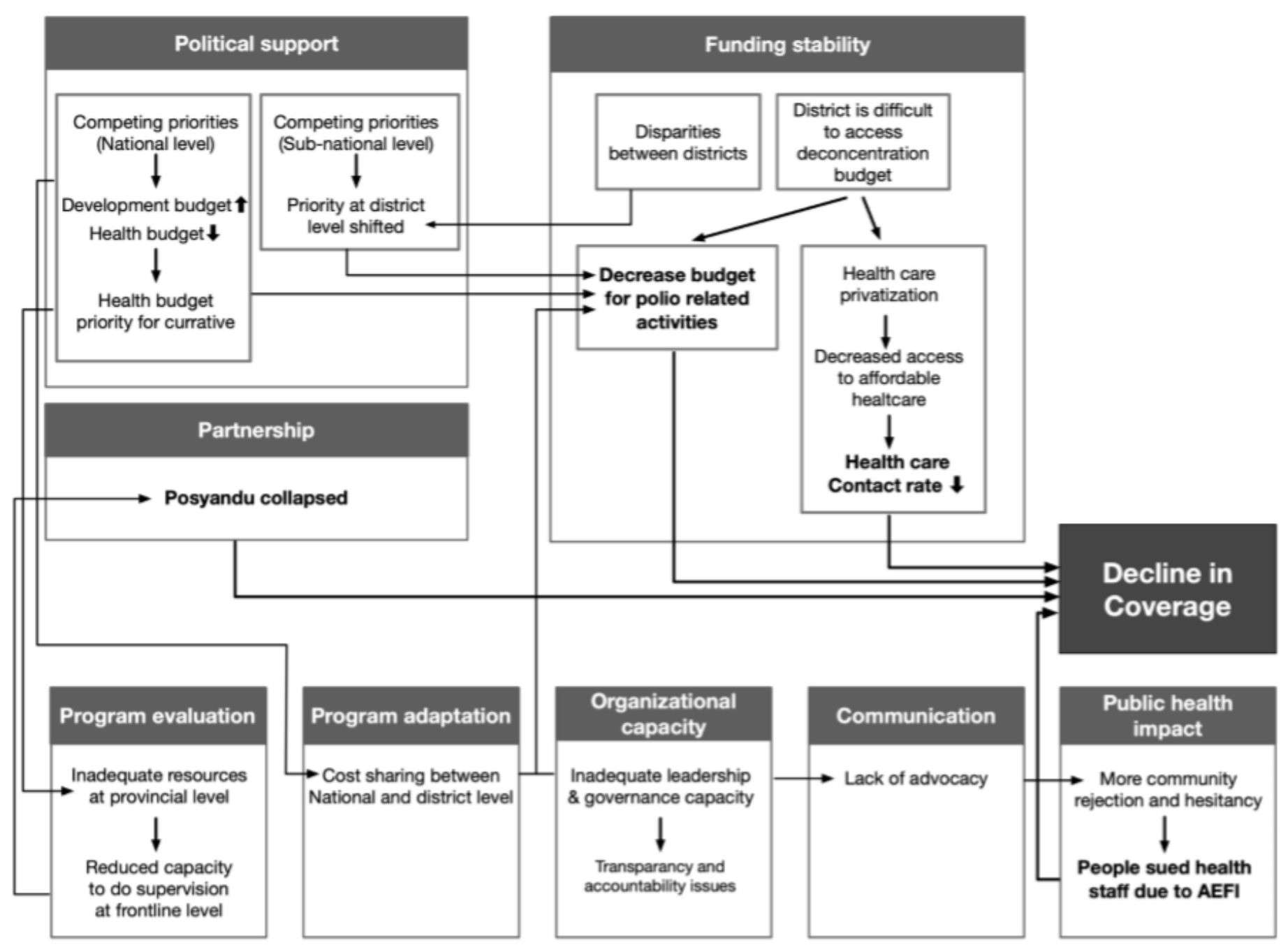

\section{Figure 2}

Problem Identified in Polio Immunization Sustainability 


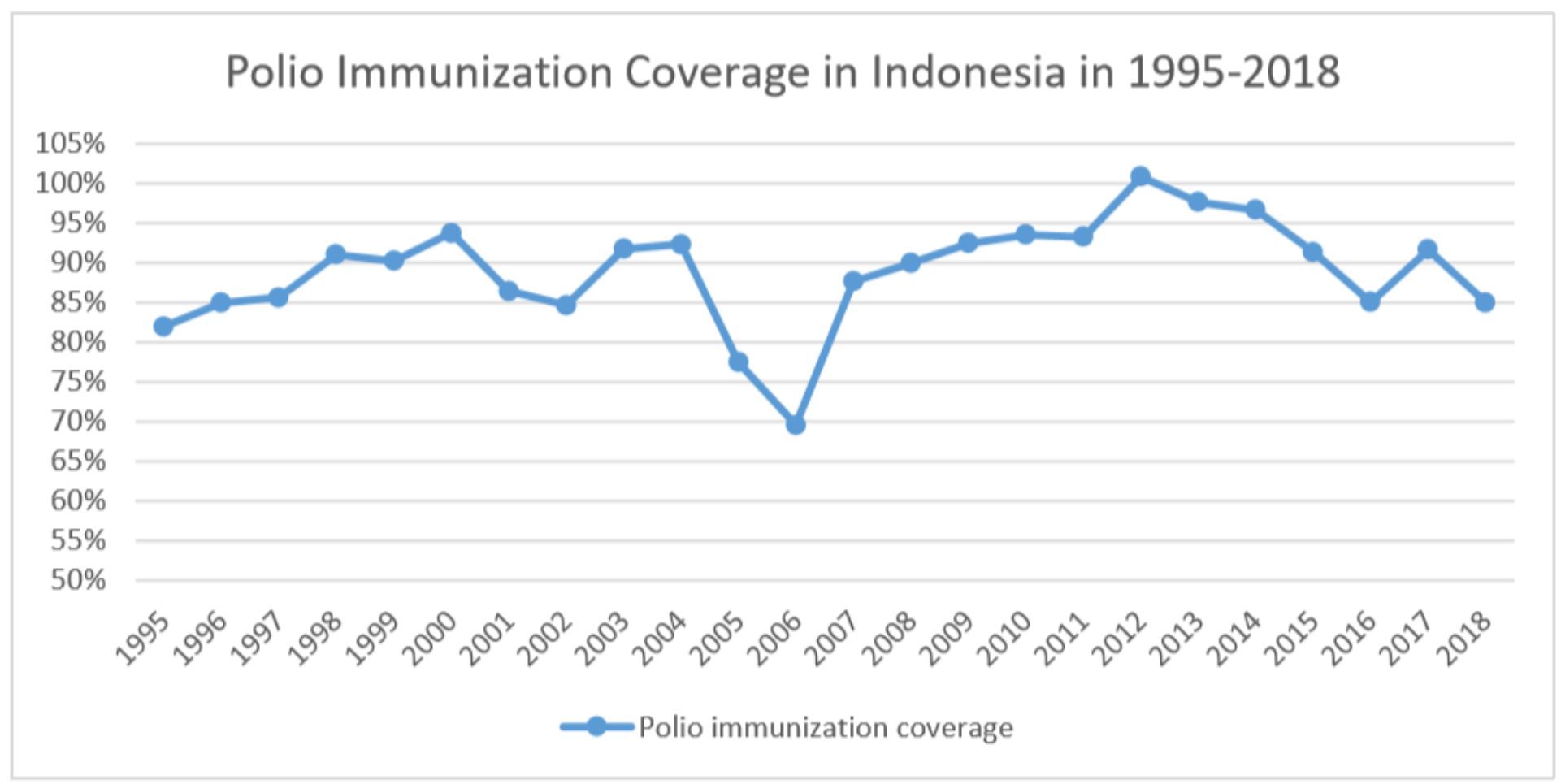

\section{Figure 3}

Polio Immunization coverage from 1995-2016 1995, 1996, 1997, 1998: 27 provinces (East Timor still included) 1999: 27 provinces (East Timor was independent, North Maluku was established) 2000: 30 provinces (Banten, Bangka Belitung, and Gorontalo were established) 2001: 31 provinces (West Papua was established) 2002: 32 provinces (Riau Islands was established) 2004: 33 provinces (West Sulawesi was established) 2012: 34 provinces (North Kalimantan was established) Sources: Sub Directorate of Immunization, $\mathrm{MoH}$ of Indonesia (unpublished)

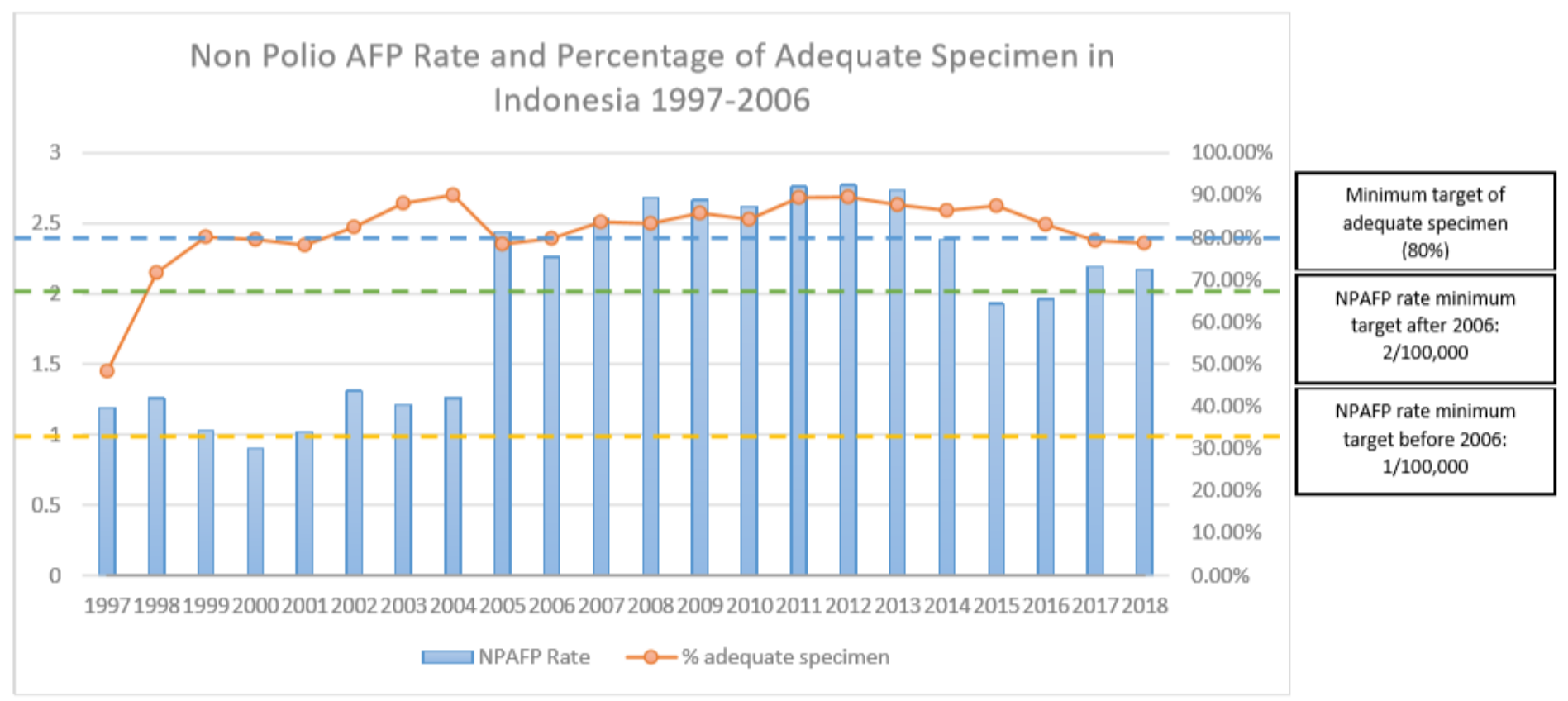




\section{Figure 4}

Non-Polio AFP (NPAFP) Rate and Adequate Specimen Percentage 1997-2018 Source: MoH of RI Decree Number 483/MENKES/SK/2007 on AFP Surveillance Guideline; Indonesia Health Profile 2007-2018

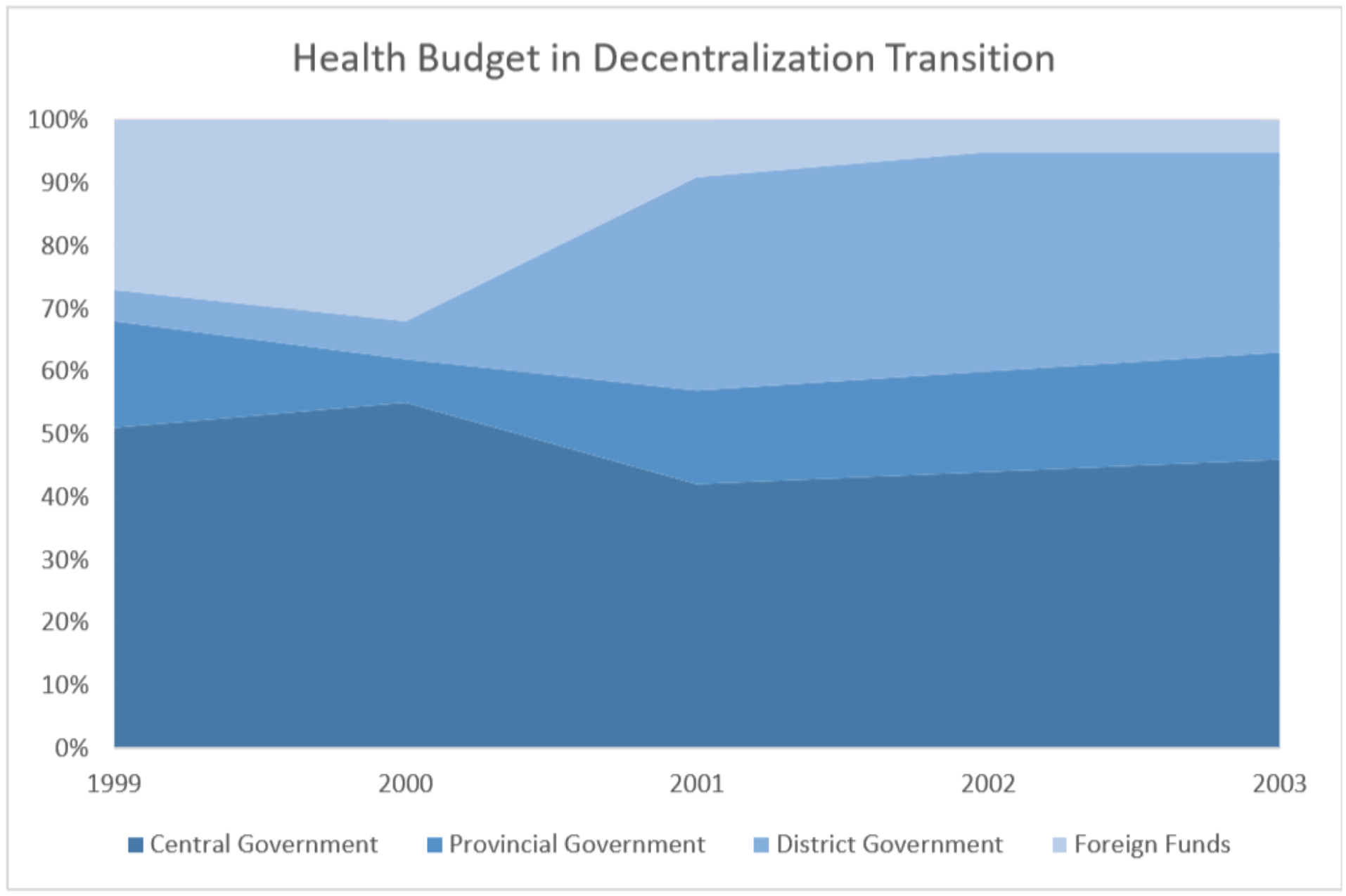

\section{Figure 5}

Health Budget Sources in Decentralization Transition Source: Desentralisasi Kesehatan (2008) (17) 


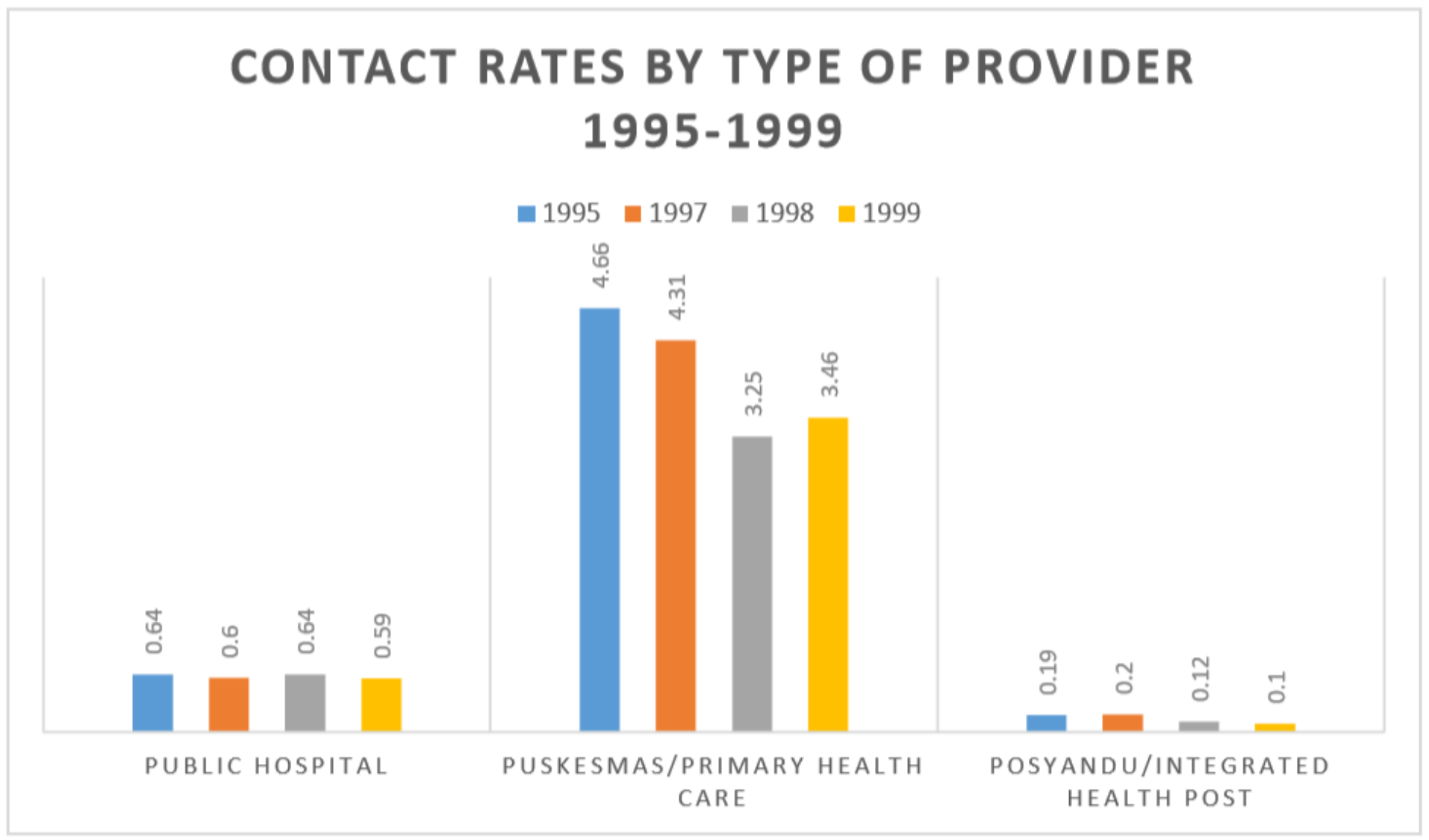

Figure 6

Contact Rates by Type of Provider 1995-1999 Source: Lieberman, 2002 (19)

\section{Supplementary Files}

This is a list of supplementary files associated with this preprint. Click to download.

- COREQChecklist260ct2020.docx 